J. Dairy Sci. 97:6622-6622

http://dx.doi.org/10.3168/jds.2014-97-10-6622

(C) American Dairy Science Association ${ }^{\circledR}, 2014$.

\title{
Erratum to "Improving accuracy of genomic predictions within and between dairy cattle breeds with imputed high-density single nucleotide polymorphism panels" (J. Dairy Sci. 95:4114-4129)
}

\author{
M. Erbe, B. J. Hayes, L. K. Matukumalli, S. Goswami, P. J. Bowman, C. M. Reich, B. A. Mason, \\ and M. E. Goddard
}

An error appeared in the equation and description of the log likelihood of the method BayesR beginning on page 4119. The corrected version is as follows:

The likelihood that SNP $i$ is in distribution $k$ is

$\log L(i, k)=-0.5 \log |\mathbf{V}|-\frac{0.5\left(\mathbf{y}^{*}{ }^{*} \mathbf{y}^{*}-\mathbf{y}^{*} \mathbf{Z}^{*} u_{k}^{*}\right)}{\sigma_{e}^{2}}+\log \left(p r_{k}\right)$,

where $\mathbf{y}^{*}$ is the vector of phenotypes corrected for all marker effects other than marker $i$, the overall mean, and the polygenic effects; $u_{k}^{*}$ is the mean of the posterior distribution of the SNP effect when assumed to be in the $k$ th distribution; $\mathbf{Z}^{*}$ is a column vector containing the SNP genotypes of all animals for SNP $i$; $\mathbf{V}$ is the variance-covariance structure of a reduced model in- cluding only the effect of the respective SNP and a residual effect; and $\log |\mathbf{V}|$ was calculated as

$$
n \log \left(\sigma_{e}^{2}\right)+\log \left(\frac{\sigma_{k}^{2} \mathbf{Z}^{*} \mathbf{Z}^{*}}{\sigma_{e}^{2}}+1\right),
$$

where $\mathbf{Z}^{*}$ contains only the information for the current SNP effect.

The authors regret the error.

\section{REFERENCES}

Erbe, M., B. J. Hayes, L. K. Matukumalli, S. Goswami, P. J. Bowman, C. M. Reich, B. A. Mason, and M. E. Goddard. 2012. Improving accuracy of genomic predictions within and between dairy cattle breeds with imputed high-density single nucleotide polymorphism panels. J. Dairy Sci. 95(7):4114-4129. 